\title{
Swedish Web Version of the Quality of Recovery Scale Adapted for Patients Undergoing Local Anesthesia and Peripheral Nerve Blockade (SwQoR-LA): Prospective Psychometric Evaluation Study
}

Ulrica Nilsson $^{1,2^{*}}, \mathrm{PhD}$; Karuna Dahlberg ${ }^{3^{*}}, \mathrm{PhD}$; Maria Jaensson ${ }^{3^{*}}, \mathrm{PhD}$

\footnotetext{
${ }^{1}$ Department of Neurobiology, Care Sciences and Society, Karolinska Institutet, Huddinge, Sweden

${ }^{2}$ Perioperative Medicine and Intensive Care, Karolinska University Hospital, Stockholm, Sweden

${ }^{3}$ School of Health Sciences, Faculty of Medicine and Health, Örebro University, Örebro, Sweden

*all authors contributed equally
}

\section{Corresponding Author:}

Ulrica Nilsson, PhD

Department of Neurobiology, Care Sciences and Society

Karolinska Institutet

Alfred Nobels Allé 23

Huddinge, 14183

Sweden

Phone: 46704203495

Email: ulrica.nilsson@ki.se

\section{Abstract}

Background: The frequency and timing of assessing patient symptoms and discomfort during postoperative recovery are goals. Therefore, real-time recovery evaluation has been suggested to identify specific deficits in patient recovery.

Objective: This study aimed to psychometrically evaluate the Swedish Web Version of the Quality of Recovery (SwQoR) Scale adapted for patients undergoing local and peripheral nerve block (SwQoR-LA).

Methods: This was a secondary analysis of a psychometric evaluation of 107 patients aged $\geq 18$ years undergoing day surgery under local or peripheral nerve block anesthesia at 4 different day surgery departments in Sweden. The SwQoR-LA, available through a mobile app called Recovery Assessment by Phone Points (RAPP), was completed daily on postoperative days 1-7.

Results: Some evidence of construct validity was supported, and discriminant validity was found in 7 of 8 items related to general anesthesia. The internal consistency was acceptable (.87-.89), and the split-half reliability was $0.80-0.86$. Cohen d effect size was 0.98 , and the percentage of change from baseline was $43.4 \%$. No floor nor ceiling effects were found.

Conclusions: The SwQoR-LA is valid, reliable, responsive, and clinically feasible for digital real-time recovery assessment of patient recovery to identify specific deficits in patient recovery and detect those patients who might benefit from a timely intervention.

Trial Registration: ClinicalTrials.gov NCT02492191; https://clinicaltrials.gov/ct2/show/NCT02492191

International Registered Report Identifier (IRRID): RR2-10.1136/bmjopen-2015-009901

(JMIR Perioper Med 2021;4(1):e23090) doi: 10.2196/23090

\section{KEYWORDS}

day surgery; local anesthesia; peripheral nerve blockade; postoperative recovery; psychometric evaluation

\section{Introduction}

Postoperative recovery is an individual process and a transformative journey to a new stable state [1]. It has a clear starting point [1], followed by a dynamic and individual process including physical, psychological, social, and habitual dimensions [1-3] that affect each other [1]. Due to advances in surgery, anesthesia, nursing care, and early mobilization, postoperative outcome and recovery have improved [4,5]. Inpatient surgery has decreased in favor of day surgery. 
Postoperative care at the hospital for day surgery patients is short, as the patients are discharged on the same day or within 24 hours [6]. This quick discharge implies that patients must take on great responsibility for their recovery process $[7,8]$. It is extremely important to follow up with and support patients in their recovery, both at the hospital and after discharge. Hence, several different patient-reported outcome questionnaires have been developed and tested and are recommended for use in clinical practice and clinical trials in surgery and anesthesia [9-11]. However, the frequency and timing of such assessment must be considered, and measurement at a single time point can be highly problematic [12]. Therefore, real-time recovery evaluation-that is, the simultaneous collection, analysis, and reporting of data occurring at different clinically relevant postoperative intervals - has been suggested to identify specific deficits in patient recovery [12-14].

To our knowledge, only one evidence-based questionnaire has been adapted for daily assessment for measuring patient-reported postoperative symptoms through an electronically assessed follow-up questionnaire: the Swedish web version of Quality of Recovery (SwQoR). The SwQoR questionnaire has been made available through an app called Recovery Assessment by Phone Points (RAPP) and includes 24 postoperative symptoms related to surgery and anesthesia [15-17]. Psychometric evaluation of the SwQoR has been performed and revealed high validity and reliability and a high degree of responsiveness; thus, the SwQoR was found to be clinically feasible for use in the systematic follow-up of patient postoperative recovery [18].

Based on experience from day surgery departments using RAPP in clinical practice, a short form for patients who have undergone day surgery under local anesthesia or peripheral nerve block has been requested. Some of the symptoms included in the SwQoR are related to general anesthesia and could therefore be excluded for the questionnaire to be more user-friendly for this group of patients. After discussion with the staff at the day surgery departments and based on our own experience, 8 symptoms related to general anesthesia were deleted from the SwQoR: sore throat, sore mouth, voice not sounding the same as usual, having trouble breathing, muscle pain, trouble urinating, diarrhea, and feeling constipated. The aim of this study was to undertake a psychometric evaluation of the real-time recovery questionnaire SwQoR-LA after adapting it for patients undergoing local anesthesia and peripheral nerve block.

\section{Methods}

\section{Study Design}

This study involved a psychometric evaluation of data originating from a multicenter, 2-group, parallel, single-blind, randomized controlled trial conducted from October 2015 to July 2016 at 4 day surgery departments in Sweden. The primary aim was to estimate the cost-effectiveness of using, vs not using, RAPP for follow-up on recovery after day surgery [19]. This study involves only those participants who were randomized into the intervention group and who underwent local or peripheral block anesthesia. This study followed the ethical standards of the Helsinki Declaration (6th revision) and was approved by the Uppsala Regional Ethics Committee (2015/262).

\section{Sample}

The data collection procedure was as follows. Information on the planned surgery was provided to the patients together with written information on the study. Upon their arrival at the day surgery department, a research nurse provided patients with oral information about the study and invited them to enroll. The inclusion criteria were age $\geq 18$ years, undergoing day surgery, able to understand written and spoken Swedish, and access to a smartphone. Exclusion criteria were memory and visual impairment, undergoing surgical abortion, and ongoing substance abuse.

\section{SwQoR-LA}

The SwQoR-LA includes 16 of the 24 postoperative symptoms included in the SwQoR. The symptoms are scored on an 11-point numeric visual analogue scale from 0 ("none of the time") to 10 ("all of the time"). Each question appears separately on the screen, and a dot on the visual analogue scale has to be moved to indicate an answer. The symptoms disappear from the screen immediately after a response is given, and each question on a symptom must be answered to submit the daily assessment [20].

\section{Procedures}

Preoperatively, the research nurse assisted with the installation of RAPP, including SwQoR, onto each participant's smartphone for both participants who underwent general and local or peripheral block anesthesia. The participants were encouraged to do a test run of the app by putting in fake responses. The research nurse also explained other functionalities of the RAPP, such as how to move between the items and how to use the navigation keys.

The participants were instructed to complete the SwQoR in the RAPP every day until postoperative day 14 . A daily reminder helped the participants to remember to send in their daily report on their recovery. The health care professionals at the day surgery department had access to all patient data via a web administrator interface.

This study includes data for the 16 symptoms (ie, SwQoR-LA) on postoperative days 1-7 from the participants that underwent local or peripheral block anesthesia. Based on the opinion of both patients and clinicians using RAPP in clinical practice, 7 days of assessment was considered appropriate, as a short recovery period after minor surgery with local or peripheral block anesthesia is expected. In addition to the SwQoR, other collected variables were age, gender, American Society of Anesthesiologists physical status, and type of anesthesia.

\section{Psychometric Evaluation}

The psychometric evaluation was guided by the COnsensus-based Standards for the selection of health Measurement INstruments (COSMIN) [21] and a previous psychometric evaluation of the SwQoR [18]. Acceptability, which measures the clinical user friendliness, was assessed in terms of the successful response rate on postoperative days 1-7. Floor and ceiling effects (ie, the number of respondents who 
achieved the lowest or highest possible scores) were measured on days 1-7; it was considered a problem if more than $15 \%$ of the study population achieved the lowest or highest possible score [22]. Construct validity is the extent to which questionnaire scores are consistent with hypotheses, assuming that the questionnaire validly measures the construct being addressed. A correlation coefficient $>0.4$ was considered to be evidence of construct validity (ie, moderate to strong correlation). To analyze construct validity, a priori hypothesis testing was conducted, under the hypothesis that the SwQoR-LA, just as with the SwQoR [18], on day 1 would correlate positively with the duration of surgery, duration of stay at the postanesthesia care unit (PACU), and patient age. In addition, lower quality of recovery (ie, higher degree of postoperative symptoms) was not expected in women versus men, just as with the SwQoR [18]. Discriminant validity was tested on day 7, and it was expected that patients who underwent local anesthesia would have significantly lower scores on the symptoms related to general anesthesia that are not included in the SwQoR-LA: voice not sounding the same as usual, sore throat, sore mouth, having trouble breathing, muscle pain, trouble urinating, diarrhea, and feeling constipated. For example, sore throat and sore mouth are symptoms related to the endotracheal tub or laryngeal mask used under general anesthesia.

Reliability was assessed with (1) internal consistency, by measuring the average correlation between the SwQoR items on days 1-7, indicated by Cronbach $\alpha$, and (2) split-half reliability, by measuring the correlation between randomly split segments of the SwQoR on days 1-7. Responsiveness, which was used to evaluate the SwQoR-LA's sensitivity and ability to detect clinically important changes, was measured with (1) Cohen $d$ effect size, calculated as average changes in scores from days 1 to 7, divided by the pooled SD of all measurements (where 0.2-0.5 indicates a small effect, 0.5-0.8 a moderate effect, and 0.8-1.2 a large effect) [23], and (2) mean changes over time and percent changes from baseline on days 1-7.

\section{Statistical Analysis}

The sample size was calculated for the original randomized controlled trial [19]; therefore, no sample size was calculated for the SwQoR-LA. Descriptive statistics are presented as means, SDs, numbers and percentages, ranges or minimum-maximum, or $95 \% \mathrm{CI}$ for the sake of clarity. In this study, when analyzing the overall level of recovery after local anesthesia, we used the global score of the SwQoR-LA, with a minimum value of 0 and a maximum value of 160 .

To investigate differences between symptoms and gender, the Mann-Whitney U-test was performed. Associations were measured with Spearman rank coefficients (rho). Cronbach $\alpha$ and split-half reliability with the Spearman-Brown coefficient were used to assess the internal consistency. SPSS version 24 (IBM Corp, Armonk, NY) for Windows was used for the statistical analyses. The null hypothesis was rejected at a two-tailed $P<.05$.

\section{Results}

\section{Acceptability}

Of the 513 patients, 19 were excluded due to cancelled operations $(n=15)$, refusal to participate $(n=3)$, or technical issues $(n=1)$, leaving 494 patients. Of the remaining patients, 107 underwent local or peripheral nerve block anesthesia, 362 underwent general anesthesia, and 25 had missing information about the type of anesthesia and were thereby excluded from the analysis. The results of this study only include the patients who underwent local anesthesia $(n=107)$, except for the discriminant validity analysis. Patients' demographic variables and perioperative factors are presented in Table 1.

The response rate was $88.8 \%(95 / 107)$ on postoperative day 1 and $72.9 \%(78 / 107)$ on day 7 . The global SwQoR-LA score decreased from 35.7 (SD 24.4) on day 1 to 15.5 (SD 15.5) on day 7 (Table 2).

Because the patients had to respond to each item in order to move on to the next item, there were no missing answers. Pain in the surgical wound was the symptom that occurred most frequently, starting with a value of 4.6 on day 1 and ending at 1.8 on day 7 (Figure 1). 
Table 1. Demographic variables and surgical and anesthetic factors $(n=107)$.

\begin{tabular}{|c|c|}
\hline Variables & Values \\
\hline \multicolumn{2}{|l|}{ Gender n (\%) } \\
\hline Male & $35(33)$ \\
\hline Female & $72(67)$ \\
\hline Age (years), mean (SD) & $49(14)$ \\
\hline Age (years), median (minimum-maximum) & $55(18-73)$ \\
\hline \multicolumn{2}{|l|}{$\mathbf{A S A}^{\mathbf{a}}, \mathbf{n}(\%)$} \\
\hline I & $31(29)$ \\
\hline II & $19(18)$ \\
\hline Missing information & $57(53)$ \\
\hline \multicolumn{2}{|l|}{ Type of anesthesia, n (\%) } \\
\hline Local infiltration & $66(62)$ \\
\hline Intravenous regional anesthesia (IVRA) & $24(22)$ \\
\hline Sciatic nerve block & $17(16)$ \\
\hline \multicolumn{2}{|l|}{ Type of surgery, $n$} \\
\hline Orthopedics & 46 \\
\hline Hand & 39 \\
\hline General & 8 \\
\hline Ear, Nose, and Throat (ENT) & 8 \\
\hline Gynecology & 3 \\
\hline Urology & 2 \\
\hline Dental & 1 \\
\hline Duration of surgery (minutes), mean (SD) & $34(25)$ \\
\hline $\mathrm{PACU}^{\mathrm{b}}$ stay (minutes), mean (SD) & $82(53)$ \\
\hline
\end{tabular}

${ }^{\mathrm{a}}$ ASA: American Society of Anesthesiologists.

${ }^{b}$ PACU: postanesthesia care unit. 
Table 2. Mean and range of the symptom scores on postoperative day $1(n=95)$.

\begin{tabular}{|c|c|c|}
\hline \multirow[t]{2}{*}{ Item } & \multicolumn{2}{|c|}{ Symptom score } \\
\hline & Mean (SD) & Minimum-maximum \\
\hline Sleeping difficulties & $2.1(2.8)$ & $0-10$ \\
\hline Not having a general feeling of well-being & $2.9(2.8)$ & $0-9$ \\
\hline Not feeling in control of my situation & $2.4(2.9)$ & $0-10$ \\
\hline Having difficulty feeling relaxed or comfortable & $2.6(2.6)$ & $0-10$ \\
\hline Depressed & $1.3(2.2)$ & $0-10$ \\
\hline Anxious & $1.6(2.4)$ & $0-10$ \\
\hline Difficulties concentrating & $1.7(2.5)$ & $0-9$ \\
\hline Having difficulty taking care of my personal hygiene & $2.9(2.9)$ & $0-10$ \\
\hline Having difficulty returning to work or usual home activities & $6.6(3.4)$ & $0-8$ \\
\hline Pain in the surgical wound & $4.6(3.0)$ & $0-10$ \\
\hline Reddened surgical wound & $1.5(2.4)$ & $0-10$ \\
\hline Swollen surgical wound & $2.1(2.8)$ & $0-10$ \\
\hline Fever & $0.3(0.9)$ & $0-4$ \\
\hline Nausea, vomiting, or both & $0.9(2.0)$ & $0-8$ \\
\hline Dizziness & $1.2(2.0)$ & $0-8$ \\
\hline Headache & $1.1(1.9)$ & $0-8$ \\
\hline
\end{tabular}

Figure 1. Pain in the surgical wound on postoperative days 1-7.

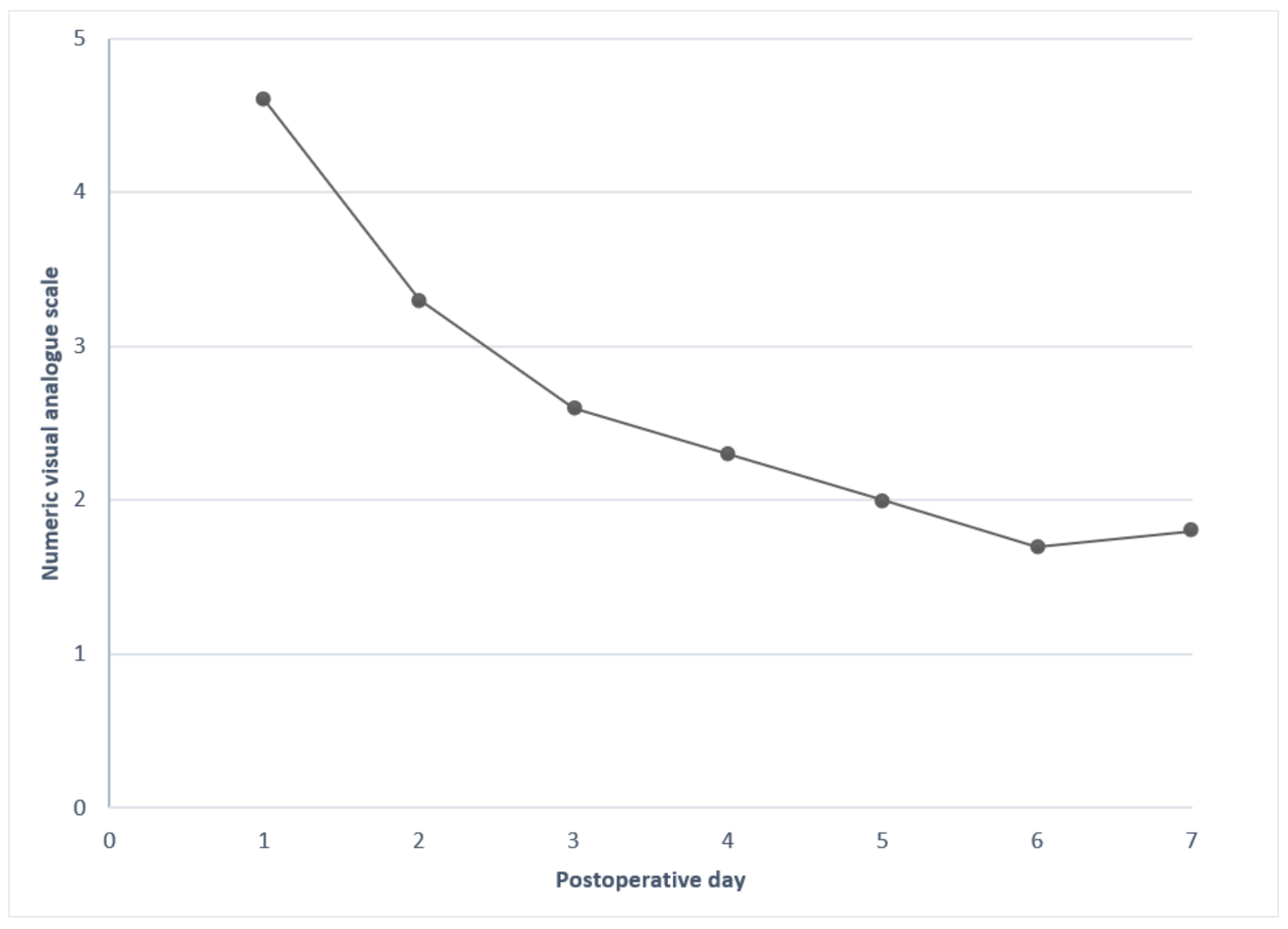




\section{Floor or Ceiling Effects}

The distributions of the SwQoR-LA scores on days 1-7 were skewed to the left and ranged between 0 and 101. No patient gave the maximum score (ie, there was no ceiling effect). No floor effects were present either (Table 3).

Table 3. Response rate, mean, minimum and maximum scores, floor effect, Cronbach $\alpha$, and split-half coefficient of the Swedish Web Version of the Quality of Recovery Scale Adapted for Patients Undergoing Local Anesthesia and Peripheral Nerve Blockade (SwQoR-LA) on postoperative days 1-7.

\begin{tabular}{llllllll}
\hline & $\begin{array}{l}\text { Day 1 } \\
(\mathrm{n}=95)\end{array}$ & $\begin{array}{l}\text { Day 2 } \\
(\mathrm{n}=90)\end{array}$ & $\begin{array}{l}\text { Day 3 } \\
(\mathrm{n}=93)\end{array}$ & $\begin{array}{l}\text { Day 4 } \\
(\mathrm{n}=89)\end{array}$ & $\begin{array}{l}\text { Day 5 } \\
(\mathrm{n}=85)\end{array}$ & $\begin{array}{l}\text { Day 6 } \\
(\mathrm{n}=80)\end{array}$ & $\begin{array}{l}\text { Day 7 } \\
(\mathrm{n}=78)\end{array}$ \\
\hline Response rate, \% & 88.8 & 84.1 & 86.9 & 83.2 & 79.4 & 74.8 & 72.9 \\
SwQoR-LA, mean (SD) & $35.7(24.4)$ & $27.0(21.7)$ & $20.5(18.6)$ & $20.0(18.1)$ & $18.0(18.2)$ & $16.8(17.1)$ & $15.5(15.5)$ \\
SwQoR-LA, minimum-maximum & $0-99$ & $0-101$ & $0-83$ & $0-85$ & $0-92$ & $0-91$ & $0-84$ \\
SwQoR-LA floor effect, $\mathrm{n}(\%)$ & $2(2.1)$ & $4(4.4)$ & $6(6.4)$ & $6(6.7)$ & $4(4.7)$ & $6(7.5)$ & $7(8.9)$ \\
Cronbach $\alpha$ & .88 & .87 & .87 & .87 & .89 & .88 & .88 \\
Split-half coefficient & 0.86 & 0.80 & 0.81 & 0.85 & 0.81 & 0.82 & 0.86 \\
\hline
\end{tabular}

\section{Validity}

Construct validity analysis indicated low correlations between the SwQoR-LA on day 1 and PACU stay (rho=0.21, $P=.05$ ), duration of surgery (rho $=0.28, P<.001)$, and patient age (rho=0.18, $P=.11$ ). There were no significant differences in global SwQoR-LA between the genders on day 1: women, 38.7 (SD 24.9) versus men, 29.8 (22.6).
Discriminant validity was determined by comparing 8 symptoms related to general anesthesia on postoperative day 1 between patients who had undergone general anesthesia and patients who had undergone local anesthesia. All symptoms except for "Diarrhea" were significantly lower in the patients who had undergone local anesthesia (Table 4).

Table 4. Discriminant validity of the Swedish Web Version of the Quality of Recovery Scale Adapted for Patients Undergoing Local Anesthesia and Peripheral Nerve Blockade (SwQoR-LA), as analyzed with Mann-Whitney U tests.

\begin{tabular}{llll}
\hline Item & General anesthesia $(\mathrm{n}=313)$, mean $(\mathrm{SD})$ & Local anesthesia $(\mathrm{n}=95)$, mean $(\mathrm{SD})$ & $P$ value \\
\hline Voice not sounding the same as usual & $1.7(2.7)$ & $0.6(1.7)$ & $<.001$ \\
Sore throat & $2.0(2.8)$ & $1.4(1.2)$ & $<.001$ \\
Sore mouth & $1.0(2.0)$ & $0.1(0.7)$ & $<.001$ \\
Having trouble breathing & $0.8(1.7)$ & $0.3(1.2)$ & .02 \\
Muscle pain & $2.2(2.8)$ & $1.4(2.2)$ & .01 \\
Trouble urinating & $1.0(2.0)$ & $0.4(1.4)$ & .01 \\
Feeling constipated & $1.2(2.3)$ & $0.6(1.6)$ & .01 \\
Diarrhea & $0.4(1.2)$ & $0.3(1.0)$ & .32 \\
\hline
\end{tabular}

\section{Reliability}

Regarding internal consistency, the Cronbach $\alpha$ for the sum score of the SwQoR-LA ranged between .87 and .89 , while the split-half coefficient ranged between 0.82 and 0.90 (Table 3).

\section{Responsiveness}

Cohen $d$ effect size between days 1 and 7 was 0.98 . The mean change in the global SwQoR-LA score from day 1 to day 7 was -19.7 (SD 19.4) with a $95 \%$ CI of $15.2-24.2, P<.001$. The percentage of change from baseline was $43.4 \%$.

\section{Discussion}

The aim of this study was to perform a psychometric evaluation of the use of a real-time recovery questionnaire for a population of day surgery patients undergoing local and peripheral block anesthesia, namely, the SwQoR-LA. To our knowledge, the SwQoR-LA is the first real-time recovery questionnaire that has been developed and tested for this specific group of patients. The SwQoR-LA was shown to have high validity, reliability, responsiveness, and clinical user friendliness. The construct validity of the SwQoR-LA was supported for PACU stay and duration of surgery, although there were low correlations. However, no significant correlations were found between age and SwQoR-LA. Strong correlations have been reported previously for patients undergoing major surgery [10,24-26]. However, due to the minor nature of the surgery and anesthesia in the present study, low correlations were expected. We found no differences between genders, which is in line with a study from Iceland [27] and an earlier publication of ours [18,28]. However, gender differences in postoperative recovery have been reported in earlier studies with inpatients undergoing surgery from Denmark [29], Iran [26], and Australia [24,25].

Discriminant validity was confirmed in 7 of the 8 symptoms that are mainly related to general anesthesia. The symptom that was not significant was "Diarrhea," possibly due to the minor 
surgery procedures. However, a symptom that that seems to be missing in SwQoR-LA is postoperative fatigue. Postoperative fatigue has been reported as a common symptom after day surgery [30] and occurs in patients, irrespective of whether general or local anesthesia is used [1,30,31]. Postoperative fatigue has a large impact on patients' daily life [31,32]. Postoperative symptoms such as early postoperative cognitive decline, [33] pain, anxiety, depression, stress, and changes in sleep patterns [34] seem to influence the severity of fatigue. However, if the symptom "Diarrhea" should be removed from SwQoR-LA in favor of the symptom "Fatigue" has to be further investigated as well as psychometrically evaluated.

Postoperative pain in the surgical wound is an important symptom to measure repeatedly and thereby identify its progression. In this study, pain in the surgical wound was the symptom that occurred most frequently, with an average level of 4.6 at day 1 . The levels decreased to 3.3 on day 2 and to $<3$ on day 3 and thereafter. In a recent study by Rodrigues et al [35], 3.8\% of the patients undergoing peripheral block and $2.1 \%$ of the patients undergoing local anesthesia suffered from uncontrolled pain on days 1-2. However, they did not assess the levels of postoperative pain as well as the progression over time.

Internal consistency of the SwQoR-LA showed acceptable values, with a Cronbach $\alpha$ range of $.87-.88$ for days 1-7. This result is in line with the SwQoR, for which Cronbach $\alpha$ ranges from .91 to .93 for days 1-7 [18]. Cronbach $\alpha$ is directly affected by scale length and increases with an increasing number of items [22]. Nevertheless, the length of the scale is not the only accurate judgment [36]. Nunnally and Bernstein [37] are frequently quoted for the following cut-off values: Cronbach $\alpha$ of at least .70 in the early stages of research; Cronbach $\alpha$ of .80 in an applied setting when cut-off scores are used and for basic research; and Cronbach $\alpha$ of .90 for scales used for clinical purposes, with a desired standard of .95 in such cases [36,37]. The SwQoR-LA should be concentrated on individual items and global scores - a recommendation that has also been made for the SwQoR [18]. Therefore, and because the sample size was too small (ie, <10 participants per item) [22], no factor analysis of the SwQoR-LA was performed.

The response rate on day 1 was $88.8 \%$ and decreased over time, with a response rate of $72.9 \%$ observed on day 7 . This decreased response rate may reflect the fact that the symptoms were low on day 7 , as the changes from baseline were $43.4 \%$, from 37.7 on day 1 to 15.5 on day 7. This finding indicates that the SwQoR-LA has the ability to detect clinically important changes [22] following day surgery in patients undergoing local and peripheral block anesthesia. In an earlier study by the same research group, the patients considered that a period of 9 days was acceptable for assessing postoperative recovery after day surgery [17]. However, that population included both patients undergoing local anesthesia and those undergoing general anesthesia [17]. As well, both patients and clinicians using RAPP in clinical practice have pointed out that 14 days of assessment is too long for the short recovery period after minor surgery with local or peripheral block anesthesia. We therefore suggest that 7 days of postoperative assessment with the SwQoR-LA is appropriate for this group of patients. Furthermore, the SwQoR-LA is a real-time recovery, electronic assessment, which is important to identify specific deficits in patient recovery $[12,13]$. As postoperative recovery is a dynamic and individual process that includes physical, psychological, social, and habitual aspects [1-3], recovery assessments should be multidimensional, be patient focused, and occur in real time at multiple clinically relevant postoperative time points [14]. The ability to identify symptom-specific recovery failure and implement targeted therapies to improve recovery is an important goal for perioperative care $[12,14]$. This requires a real-time recovery questionnaire such as the SwQoR-LA for early identification of recovery failure as well as for assessment of the outcomes following interventions in clinical practice and clinical trials [12]. If access to the web version of the SwQoR-LA is not possible, the paper version can be used instead, as there is equivalence between the web version and paper version [17].

\section{Limitations}

There are some limitations in our study. First, the sample size is relatively small, but considered sufficient for examining psychometric properties with 16 items. However, there is no consensus about the number of participants for each type of psychometric analysis. To analyze construct validity, responsiveness, and floor and ceiling effects, a sample size of at least 50 participants is recommended [22]. Second, no test-retest reliability was conducted. This feature could be improved in future studies by involving a larger pool of patients undergoing a wider range of peripheral nerve block. Third, the duration for data entry was not measured.

\section{Conclusions}

To our knowledge, this study is the first to evaluate a real-time recovery questionnaire, the SwQoR-LA, in patients undergoing local or peripheral nerve block anesthesia. The SwQoR-LA is valid, reliable, responsive, and clinically feasible for the real-time assessment of patient recovery in order to detect those patients who might benefit from timely follow-up and intervention.

\section{Acknowledgments}

This study is supported by FORTE (the Swedish Research Council for Health, Working Life and Healthcare), grant number 2013-4765, and Vetenskapsrådet (the Swedish Research Council), grant number 2015-02273.

\section{Conflicts of Interest}

Author UN and the Örebro University Enterprise AB hold shares in RAPP-AB. None of the other authors have any potential conflicts of interest. 


\section{References}

1. Nilsson U, Jaensson M, Hugelius K, Arakelian E, Dahlberg K. A journey to a new stable state-further development of the postoperative recovery concept from day surgical perspective: a qualitative study. BMJ Open 2020 Sep 23;10(9):e037755 [FREE Full text] [doi: 10.1136/bmjopen-2020-037755] [Medline: $\underline{32967881]}$

2. Allvin R, Berg K, Idvall E, Nilsson U. Postoperative recovery: a concept analysis. J Adv Nurs 2007 Mar;57(5):552-558. [doi: 10.1111/j.1365-2648.2006.04156.x] [Medline: 17284272]

3. Lundmark M, Lennerling A, Almgren M, Forsberg A. Recovery after lung transplantation from a patient perspective proposing a new framework. J Adv Nurs 2016 Dec 19;72(12):3113-3124. [doi: 10.1111/jan.13058] [Medline: 27346667]

4. Nilsson U, Gruen R, Myles PS. Postoperative recovery: the importance of the team. Anaesthesia 2020 Jan 05;75 Suppl 1(S1):e158-e164 [FREE Full text] [doi: 10.1111/anae.14869] [Medline: 31903575]

5. Weiser TG, Haynes AB, Molina G, Lipsitz SR, Esquivel MM, Uribe-Leitz T, et al. Estimate of the global volume of surgery in 2012: an assessment supporting improved health outcomes. The Lancet 2015 Apr;385:S11. [doi: 10.1016/s0140-6736(15)60806-6]

6. Darwin L. Patient selection for day surgery. Anaesthesia \& Intensive Care Medicine 2016 Mar;17(3):151-154. [doi: 10.1016/j.mpaic.2015.12.002]

7. Berg K, Arestedt K, Kjellgren K. Postoperative recovery from the perspective of day surgery patients: a phenomenographic study. Int J Nurs Stud 2013 Dec;50(12):1630-1638. [doi: 10.1016/j.ijnurstu.2013.05.002] [Medline: 23726224]

8. Dahlberg K, Jaensson M, Nilsson U, Eriksson M, Odencrants S. Holding It Together-Patients' Perspectives on Postoperative Recovery When Using an e-Assessed Follow-Up: Qualitative Study. JMIR Mhealth Uhealth 2018 May 25;6(5):e10387 [FREE Full text] [doi: 10.2196/10387] [Medline: 29802094]

9. Gornall B, Myles P, Smith C, Burke J, Leslie K, Pereira M, et al. Measurement of quality of recovery using the QoR-40: a quantitative systematic review. Br J Anaesth 2013 Aug;111(2):161-169 [FREE Full text] [doi: 10.1093/bja/aet014] [Medline: 23471753]

10. Kleif J, Waage J, Christensen K, Gögenur I. Systematic review of the QoR-15 score, a patient- reported outcome measure measuring quality of recovery after surgery and anaesthesia. Br J Anaesth 2018 Jan;120(1):28-36 [FREE Full text] [doi: 10.1016/j.bja.2017.11.013] [Medline: 29397134]

11. Bowyer A, Jakobsson J, Ljungqvist O, Royse C. A review of the scope and measurement of postoperative quality of recovery. Anaesthesia 2014 Nov 02;69(11):1266-1278 [FREE Full text] [doi: 10.1111/anae.12730] [Medline: 24888412]

12. Ladha K, Wijeysundera DN. Role of patient-centred outcomes after hospital discharge: a state-of-the-art review. Anaesthesia 2020 Jan;75 Suppl 1:e151-e157 [FREE Full text] [doi: 10.1111/anae.14903] [Medline: $\underline{31903568]}$

13. Bowyer AJ, Royse CF. Postoperative recovery and outcomes--what are we measuring and for whom? Anaesthesia 2016 Jan 01;71 Suppl 1:72-77 [FREE Full text] [doi: 10.1111/anae.13312] [Medline: 26620150]

14. Bowyer A, Royse C. The importance of postoperative quality of recovery: influences, assessment, and clinical and prognostic implications. Can J Anaesth 2016 Feb 16;63(2):176-183. [doi: 10.1007/s12630-015-0508-7] [Medline: 26475163]

15. Jaensson M, Dahlberg K, Eriksson M, Grönlund A, Nilsson U. The Development of the Recovery Assessments by Phone Points (RAPP): A Mobile Phone App for Postoperative Recovery Monitoring and Assessment. JMIR Mhealth Uhealth 2015 Sep 11;3(3):e86 [FREE Full text] [doi: 10.2196/mhealth.4649] [Medline: 26362403]

16. Jaensson M, Nilsson U. Impact of changing positively worded items to negatively worded items in the Swedish web-version of the Quality of Recovery (SwQoR) questionnaire. J Eval Clin Pract 2017 Jun 21;23(3):502-507. [doi: 10.1111/jep.12639] [Medline: 27650792]

17. Dahlberg K, Jaensson M, Eriksson M, Nilsson U. Evaluation of the Swedish Web-Version of Quality of Recovery (SwQoR): Secondary Step in the Development of a Mobile Phone App to Measure Postoperative Recovery. JMIR Res Protoc 2016 Sep 28;5(3):e192 [FREE Full text] [doi: 10.2196/resprot.5881] [Medline: 27679867]

18. Nilsson U, Dahlberg K, Jaensson M. The Swedish Web Version of the Quality of Recovery Scale Adapted for Use in a Mobile App: Prospective Psychometric Evaluation Study. JMIR Mhealth Uhealth 2017 Dec 03;5(12):e188 [FREE Full text] [doi: 10.2196/mhealth.9061] [Medline: 29229590]

19. Nilsson U, Jaensson M, Dahlberg K, Odencrants S, Grönlund Å, Hagberg L, et al. RAPP, a systematic e-assessment of postoperative recovery in patients undergoing day surgery: study protocol for a mixed-methods study design including a multicentre, two-group, parallel, single-blind randomised controlled trial and qualitative interview studies. BMJ Open 2016 Jan 13;6(1):e009901 [FREE Full text] [doi: 10.1136/bmjopen-2015-009901] [Medline: 26769788]

20. Jaensson M, Dahlberg K, Eriksson M, Nilsson U. Evaluation of postoperative recovery in day surgery patients using a mobile phone application: a multicentre randomized trial. Br J Anaesth 2017 Nov 01;119(5):1030-1038 [FREE Full text] [doi: 10.1093/bja/aex331] [Medline: 29077818]

21. Mokkink LB, Terwee CB, Patrick DL, Alonso J, Stratford PW, Knol DL, et al. The COSMIN checklist for assessing the methodological quality of studies on measurement properties of health status measurement instruments: an international Delphi study. Qual Life Res 2010 May 19;19(4):539-549 [FREE Full text] [doi: 10.1007/s11136-010-9606-8] [Medline: 20169472] 
22. Terwee CB, Bot SD, de Boer MR, van der Windt DA, Knol DL, Dekker J, et al. Quality criteria were proposed for measurement properties of health status questionnaires. J Clin Epidemiol 2007 Jan;60(1):34-42. [doi: 10.1016/j.jclinepi.2006.03.012] [Medline: 17161752]

23. Sawilowsky SS. New Effect Size Rules of Thumb. J. Mod. App. Stat. Meth 2009 Nov 01;8(2):597-599. [doi: $10.22237 /$ jmasm/1257035100]

24. Myles PS, Weitkamp B, Jones K, Melick J, Hensen S. Validity and reliability of a postoperative quality of recovery score: the QoR-40. Br J Anaesth 2000 Jan;84(1):11-15 [FREE Full text] [doi: 10.1093/oxfordjournals.bja.a013366] [Medline: 10740540]

25. Stark P, Myles P, Burke JA. Development and psychometric evaluation of a postoperative quality of recovery score: the QoR-15. Anesthesiology 2013 Jun;118(6):1332-1340 [FREE Full text] [doi: 10.1097/ALN.0b013e318289b84b] [Medline: 23411725]

26. Yaghoobi S, Hamidfar M, Lawson DM, Fridlund B, Myles PS, Pakpour AH. Validity and reliability of the Iranian version of the quality of recovery-40 questionnaire. Anesth Pain Med 2015 Apr 20;5(2):e20350 [FREE Full text] [doi: 10.5812/aapm.20350] [Medline: 25893185]

27. Sveinsdottir H, Borgthorsdottir T, Asgeirsdottir MT, Albertsdottir K, Asmundsdottir LB. Recovery After Same-Day Surgery in Patients Receiving General Anesthesia: A Cohort Study Using the Quality of Recovery-40 Questionnaire. J Perianesth Nurs 2016 Dec;31(6):475-484. [doi: 10.1016/j.jopan.2015.07.003] [Medline: 27931699]

28. Jaensson M, Dahlberg K, Nilsson U. Sex Similarities in Postoperative Recovery and Health Care Contacts Within 14 Days With mHealth Follow-Up: Secondary Analysis of a Randomized Controlled Trial. JMIR Perioper Med 2018 Mar 26;1(1):e2. [doi: 10.2196/periop.9874]

29. Kleif J, Edwards HM, Sort R, Vilandt J, Gögenur I. Translation and validation of the Danish version of the postoperative quality of recovery score QoR-15. Acta Anaesthesiol Scand 2015 Aug 13;59(7):912-920. [doi: 10.1111/aas.12525] [Medline: $\underline{25867135}$ ]

30. Mendy N, Moriceau J, Sacuto Y, Besnier E, Clavier T, Ndangang M, et al. Postoperative fatigue after day surgery: prevalence and risk factors. A prospective observational study. Minerva Anestesiol 2020 Dec;86(12). [doi: $10.23736 / \mathrm{s} 0375-9393.20 .14358-\mathrm{x}]$

31. Nilsson U, Jaensson M, Dahlberg K, Hugelius K. Postoperative Recovery After General and Regional Anesthesia in Patients Undergoing Day Surgery: A Mixed Methods Study. J Perianesth Nurs 2019 Jun;34(3):517-528 [FREE Full text] [doi: 10.1016/j.jopan.2018.08.003] [Medline: 30470465]

32. Gilmartin J. Contemporary day surgery: patients' experience of discharge and recovery. J Clin Nurs 2007 Jun;16(6):1109-1117. [doi: 10.1111/j.1365-2702.2007.01548.x] [Medline: 17518885]

33. Fan Y, Yuan L, Ji M, Yang J, Gao D. The effect of melatonin on early postoperative cognitive decline in elderly patients undergoing hip arthroplasty: A randomized controlled trial. J Clin Anesth 2017 Jun;39:77-81. [doi: 10.1016/j.jclinane.2017.03.023] [Medline: 28494914]

34. Zargar-Shoshtari K, Hill AG. Postoperative fatigue: a review. World J Surg 2009 Apr 3;33(4):738-745. [doi: 10.1007/s00268-008-9906-0] [Medline: 19189174]

35. Rodrigues NM, Ribeiro P, Jesus F, Caldeira M. Pain in Ambulatory Surgery: 4-Year Experience of an Ambulatory Surgery Unit in a Tertiary Hospital. Ambulatory Surgery 2020;26(1):14-16.

36. Yang Y, Green SB. Coefficient Alpha: A Reliability Coefficient for the 21st Century? Journal of Psychoeducational Assessment 2011 May 19;29(4):377-392. [doi: 10.1177/0734282911406668]

37. Nunnally J, Bernstein I. Psychometric theory, 3rd edition. New York, NY: McGraw-Hill; 1994:1994.

\section{Abbreviations}

COSMIN: COnsensus-based Standards for the selection of health Measurement INstruments

PACU: postanesthesia care unit

RAPP: Recovery Assessment by Phone Points

SwQoR-LA: Swedish Web Version of the Quality of Recovery Scale Adapted for Patients Undergoing Local Anesthesia and Peripheral Nerve Blockade 
Edited by G Eysenbach; submitted 31.07.20; peer-reviewed by K Li, J Odom-Forren; comments to author 01.12.20; revised version received 04.12.20; accepted 19.12.20; published 15.01.21

Please cite as:

Nilsson U, Dahlberg K, Jaensson $M$

Swedish Web Version of the Quality of Recovery Scale Adapted for Patients Undergoing Local Anesthesia and Peripheral Nerve

Blockade (SwQoR-LA): Prospective Psychometric Evaluation Study

JMIR Perioper Med 2021;4(1):e23090

URL: http://periop.jmir.org/2021/1/e23090/

doi: $\frac{10.2196 / 23090}{D: 3344832}$

PMID: 33448932

(CUlrica Nilsson, Karuna Dahlberg, Maria Jaensson. Originally published in JMIR Perioperative Medicine (http://periop.jmir.org), 15.01.2021. This is an open-access article distributed under the terms of the Creative Commons Attribution License (https://creativecommons.org/licenses/by/4.0/), which permits unrestricted use, distribution, and reproduction in any medium, provided the original work, first published in JMIR Perioperative Medicine, is properly cited. The complete bibliographic information, a link to the original publication on http://periop.jmir.org, as well as this copyright and license information must be included. 